\title{
Quantitative Effect of Micro-particles in Iron Ore on the Optimum Granulation Moisture
}

\author{
Shinji KAWACHI and Shunji KASAMA \\ Ironmaking R \& D Div., Environmental \& Process Technology Center, Nippon Steel Corp., 20-1 Shintomi, Futtsu, Chiba 293- \\ 8511 Japan.
}

(Received on October 9, 2008; accepted on December 5, 2008; originally published in Tetsu-to-Hagané, Vol. 94, 2008, No. 11, pp. 475-482)

\begin{abstract}
Anionic polymer dispersant (APD) has been applied to the granulation process for enhancing sintering productivity. It is reported that APD accelerates micro-particle dispersion. In this study, the amount of microparticles whose diameter was less than $10 \mu \mathrm{m}$ has been surveyed by means of Andreasen pipette method. And in order to understand granulation mechanism focused on micro-particle, effect of micro-particles on granulation has been analyzed by granulation test with single ore. As results, total amount of micro-particle was in the range from 2 to $10 \%$ in all ores. The increase in amount of micro-particles by APD differed according to ores. These differences mostly could be explained with mineral characteristics of micro-particle. From the granulation test, the optimum moisture in wet state did not correspond with one in dry state. In wet state, micro-particles dispersed by APD increased effective volume of water, resulting in lowing water requirement for optimum granulation. Therefore, APD addition is seemed to enable optimum moisture of granulation to move wet optimum moisture closer to dry optimum moisture. In dry state, dispersing microparticles may result in concentrating in contact point of iron ores and reinforces the strength of granules. This understanding based on this result can make comprehensive interpretation for granulation.
\end{abstract}

KEY WORDS: agglomeration; iron ore sintering; granulation; moisture; micro-particle; anionic-polymer-dispersant;

\section{Introduction}

Reflecting the ever-increasing demand for steel on a global basis, Japan's annual crude steel output has been more than 120 million tons in recent years. Japanese steelmakers are taking specific measures to improve the productivity of their blast furnace operation. In order to enhance the blast furnace productivity still more, it is desirable to increase the using amount of sinter, which can be reduced and dropped more easily than lump ore, as the source of iron.

To enhance the productivity of sinter, steelmakers have positively expanded the equipment i.e. increasing the pallet width, extending the strand to widen the sintering area and increasing the blower capacity to allow for sintering operation under higher suction pressure, etc. Although these methods require huge amounts of investment, they significantly enhance the productivity of sinter. In fact, many steelworks have benefited much from them.

The productivity of sinter is strong function of gas flow velocity. Various technologies for improving the permeability of the sintering bed by controlling the packing structure of the entire sintering bed have also been developed. They include: the stand sintering ${ }^{1)}$ for restraining the sintering bed from shrinking, the ventilating bar $^{2}$ ) for securing sufficient ventilation pores in the raw material bed, intensified sifting feeder (ISF) for segregation charging ${ }^{3)}$ and magnetic braking feeder for low packing structure of raw material bed, ${ }^{4)}$ etc. All these technologies play an important role in increasing the production of sinter.

Advancement of iron ore granulation is effective for improving the permeability of raw material bed. Granulation technologies have also been studied actively since the 1970 s. For example, the addition of a binder (quicklime, etc.) for strengthening the bond between iron ores, ${ }^{5-7)}$ the disk pelletizer for increasing the bulk density of granules, ${ }^{8)}$ and the high-speed agitating mixer having excellent mixing performance that allows effective utilization of clay contained in certain ores ${ }^{9-11)}$ have been developed and applied widely. These techniques have been discussed based on a granules composed of nuclear particle and fine particles stuck by the action of water bridging. ${ }^{12-14)}$ Recently, Okada et al. ${ }^{15)}$ has found that not only the water bridge but also the behavior of micro-particles which are smaller than the fine particles influences the granulation. On the basis of their finding, they have developed a new granulation technology using a dispersant binder. This new binder technology is that micro-particles of iron ore are dispersed into water by the dispersant, resulting in strengthening the points of contact between the nuclear particles and fine particles or among the fine particles.

Although Okada et al. has clarified the granulation mechanism with focus on the behavior of micro-particles qualitatively, it has not been investigated quantitatively. In 
the present study, with the aim of clarifying the granulation mechanism from a new viewpoints was attempted the behavior of micro-particles in iron ore was quantified and the intrinsic effect of micro-particles on the granulation of iron ore in wet state and the degradation of granule in dry state was analyzed.

\section{Experimental}

The amount of micro-particles in iron ore was standardized in the present study. The iron ore was varied 7 representative iron ores to investigate the difference of ore type. In addition, the effect of micro-particles on granulation of iron ore in wet and dry state was investigated by granulation test.

\subsection{Samples}

The ores used are shown in Table 1. Samples A-D are Australian iron ores. Ore A is high-alumina pisolite ore, Ore B is low-alumina pisolite ore, Ore C is Maramamba ore and Ore D is high-phosphorus Blockman ore. Ores E and F are Brazilian hematite iron ores. Ore E has a relatively porous structure, whereas Ore $\mathrm{F}$ has a very dense structure-the densest of all the samples. Ore $G$ is Indian hematite ore.

For the purpose of the experiment, each of ores was completely dried and sieved into six sizes; above $5 \mathrm{~mm}, 5$ to $2 \mathrm{~mm}, 2$ to $1 \mathrm{~mm}, 1$ to $0.5 \mathrm{~mm}, 0.5$ to $0.25 \mathrm{~mm}$ and below $0.25 \mathrm{~mm}$.

\subsection{Quantification of Micro-particles}

The amount of micro-particles contained in each ore was measured by the particle settling method ${ }^{16)}$ using a $1000 \mathrm{~mL}$ Andreasen pipette. The Andreasen pipette is schematically shown in Fig. 1. First, $10 \mathrm{~g}$ of the sample, $300 \mathrm{~mL}$ of pure water and anionic polymer dispersant (APD) were mixed in a beaker and the mixture was stirred by ultrasonic wave for $3 \mathrm{~min}$. For each sample, the amount of APD addition was varied in four levels: 0 mass $\%$, $0.05 \mathrm{mass} \%, 0.50 \mathrm{mass} \%$ and 5.00 mass $\%$. Next, the agitated suspension and ore particles were removed into the Andreasen pipette and added with $700 \mathrm{~mL}$ of pure water, and the mixture was stirred by shaking the pipette three times. After that, the pipette was left undisturbed for $20 \mathrm{~min}$. Then, $10 \mathrm{~mL}$ of the suspension was collected from the level $200 \mathrm{~mm}$ under the surface of suspension, and the weight of the solid obtained after drying the sample suspension completely was measured.

Assuming the density of particles collected by this method as $4000 \mathrm{~kg} / \mathrm{m}^{3}$, which falls between the density of hematite and the density of gangue, the upper limit of the particle diameter can be regarded to be approximately $10 \mu \mathrm{m}$ from Stokes' expression (1). In this paper, the values of the parameters, $t, h, M, V$ and $v$, in expressions (1) to (4) were assumed to be $1200 \mathrm{~s}, 0.2 \mathrm{~m}, 10^{-2} \mathrm{~kg}, 10^{-3} \mathrm{~m}^{3}$ and $10^{-5} \mathrm{~m}^{3}$, respectively, the collected suspension particles were defined as micro-particles, and the amount of microparticles in iron ore was obtained by expression (2). $R$ represents the mass $\%$ of micro-particles in the iron ore under consideration.
Table 1. Chemical composition of sample ores.

\begin{tabular}{|c|c|c|c|c|}
\hline & $\mathrm{T} . \mathrm{Fe}$ & $\mathrm{Al}_{2} \mathrm{O}_{3}$ & $\mathrm{SiO}_{2}$ & C.W \\
\hline Ore A & 56.8 & 2.75 & 6.01 & 7.80 \\
\hline Ore B & 58.2 & 1.45 & 5.11 & 9.31 \\
\hline Ore C & 61.2 & 2.35 & 3.50 & 5.80 \\
\hline Ore D & 63.5 & 2.23 & 3.88 & 2.16 \\
\hline Ore E & 66.4 & 0.69 & 3.20 & 0.96 \\
\hline Ore F & 67.7 & 0.70 & 0.74 & 1.05 \\
\hline Ore G & 62.5 & 1.78 & 2.13 & 4.26 \\
\hline
\end{tabular}

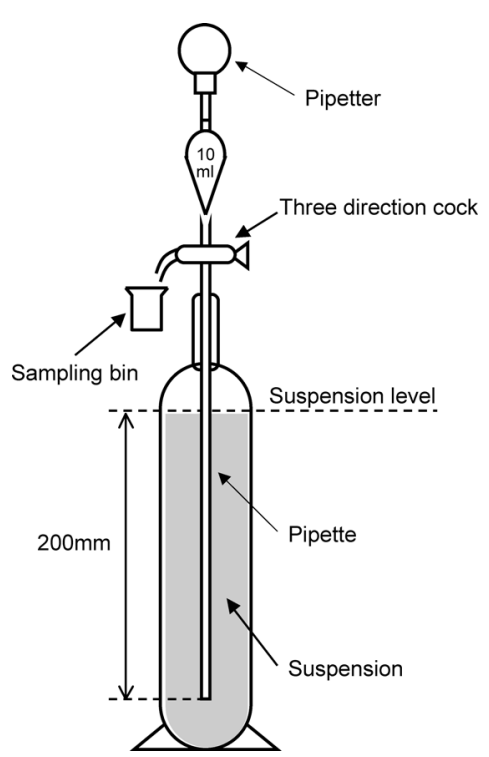

Fig. 1. Schematic of Andreasen pipette.

$$
\begin{array}{r}
D=\left\{\left(18 \mu h /\left(\left(\rho_{\mathrm{s}}-\rho_{\mathrm{f}}\right) g t\right)\right)\right\}^{1 / 2} \\
R=100 \times(1-\alpha) \times C_{t} / C_{0} \ldots \ldots \\
C_{0}=M / V \ldots \ldots \ldots \ldots \ldots \ldots \ldots \ldots \ldots \ldots \ldots \ldots \ldots \\
C_{t}=m / v \ldots \ldots \ldots \ldots \ldots \ldots
\end{array}
$$

$D: \quad$ Stokes diameter $(\mathrm{m})$

$\mu$ : Fluid viscosity $(\mathrm{kg} / \mathrm{m} / \mathrm{s})$

$t$ : Time for which pipette is left undisturbed (s)

$\rho_{\mathrm{f}}$ : Fluid density $\left(\mathrm{kg} / \mathrm{m}^{3}\right)$

$g$ : Gravitational acceleration $\left(\mathrm{m} / \mathrm{s}^{2}\right)$

$\rho_{\mathrm{s}}$ : Powder density $\left(\mathrm{kg} / \mathrm{m}^{3}\right)$

$R$ : Amount of micro-particles (mass $\%$ )

$h$ : Distance from pipette front end to suspension level (m)

$C_{t}$ : Particle concentration at pipette front end at time $t$ $\left(\mathrm{kg} / \mathrm{m}^{3}\right)$

$C_{0}$ : Overall particle concentration at start of settling $\left(\mathrm{kg} / \mathrm{m}^{3}\right)$

$\alpha$ : APD concentration ( $\mathrm{kg}-\mathrm{APD} / \mathrm{kg}$-ore)

$M:$ Initial mass of sample $(\mathrm{kg})$

$V:$ Andreasen pipette volume $\left(\mathrm{m}^{3}\right)$

$m$ : Mass of solid in collected suspension $(\mathrm{kg})$

$v$ : Amount of suspension collected $\left(\mathrm{m}^{3}\right)$

\subsection{Observation of Ore Surfaces and Micro-particles}

In order to examine the forms of micro-particles in iron ores, the surfaces of 2 to $5 \mathrm{~mm}$ iron ores were observed before and after ultrasonic agitation by a scanning electron 
Table 2. Size distributions of iron ores for granulation test.

\begin{tabular}{|c|c|}
\hline Size $(\mathrm{mm})$ & Ratio $(\mathrm{mass} \%)$ \\
\hline $10 \sim 5$ & 15.4 \\
\hline $5 \sim 2$ & 23.0 \\
\hline $2 \sim 1$ & 15.0 \\
\hline $1 \sim 0.5$ & 12.2 \\
\hline $0.5 \sim 0.25$ & 10.6 \\
\hline-0.25 & 23.8 \\
\hline
\end{tabular}

microscope (SEM). Micro-particles collected by the particle settling method, dried and formed into sheets under a pressure of $6.2 \mathrm{GPa}$ were also subjected to surface observation under the SEM.

\subsection{Granulation Test}

The effect of APD on the granulation of ore in wet state and the degradation of granule in dry state was quantitatively evaluated by granulation test. The samples were used in size distribution shown in Table 2.

In the granulation test, a drum mixer (ID: $380 \mathrm{~mm}$, width: $140 \mathrm{~mm}$ ) was used. For each iron ore, $3 \mathrm{~kg}$ of sample having the reference size distribution was mixed in the drum mixer for $60 \mathrm{~s}$, added with water and APD, and subjected to the granulation test for $240 \mathrm{~s}$. For each iron ore, two levels of the amount of APD were used, 0 mass $\%$ and 0.5 mass $\%$, and moisture was varied between 5 mass $\%$ and $10 \mathrm{mass} \%$. $600 \mathrm{~g}$ granules were dried to $3 \pm 1 \mathrm{mass} \%$ moisture at $105^{\circ} \mathrm{C}$. They were then manually sieved into the six classes of particle size and the mass of particles of each size class was measured. This size distribution was defined as the wet size distribution, which was used to evaluate the granulation test results. And $200 \mathrm{~g}$ granules were completely dried and subjected to Ro-Tap Sieve Shaker treatment for $300 \mathrm{~s}$. Then, the proportion of $0.25 \mathrm{~mm}$ or less particles was measured to evaluate the degradation of granules in dry state.

\section{Results}

\subsection{Amount of Micro-particles Contained in Iron Ore}

The amount of micro-particles of each ores is shown in Table 3, and Fig. 2. In Fig. 2, each of the black area indicates the increase in micro-particles dispersed by APD. It can be seen that APD increased the micro-particles by 2 to 10 mass $\%$, despite the fact that all the ores had been dried and classified by particle size. Characteristically, extent of the increase in micro-particles by APD was varied with in iron ore type. Ore C (Maramamba ore) showed the largest increase in micro-particles by APD, with the maximum exceeding 10 mass $\%$. Ores A and B (pisolite ores) showed a relatively large amount of micro-particles, 5.7 to 7.5 mass $\%$, even without APD. The micro-particles in these two ores did not increase noticeably even with APD. Ore F contained a very small amount of micro-particles - about 2 mass \% even after APD addition. Thus, the micro-particles dispersion was markedly different from ore type. Concerning the effect of the amount of APD on the increase in micro-particles, any ores did not show a significant difference in the micro-particles even when the amount of APD was varied from 0.05 to 0.5 to 5 mass $\%$. It is considered
Table 3. Content of micro-particle in each split size for ores.

\begin{tabular}{|c|c|c|c|c|c|c|c|c|}
\hline & \multirow[b]{2}{*}{$\begin{array}{c}\text { APD } \\
(\text { mass } \%)\end{array}$} & \multicolumn{7}{|c|}{ Micro-particle (mass\%) } \\
\hline & & $+5 \mathrm{~mm}$ & $\begin{array}{l}2 \sim \\
5 \mathrm{~mm}\end{array}$ & $\begin{array}{l}1 \sim \\
2 \mathrm{~mm}\end{array}$ & \begin{tabular}{|c|}
$0.5 \sim$ \\
$1 \mathrm{~mm}$
\end{tabular} & $\begin{array}{l}0.25 \sim \\
0.5 \mathrm{~mm}\end{array}$ & $\begin{array}{r}-0.25 \\
\mathrm{~mm} \\
\end{array}$ & Average \\
\hline \multirow{4}{*}{$\begin{array}{c}\text { Ore } \\
\mathrm{A}\end{array}$} & $\begin{array}{l}0.0 \\
\end{array}$ & 1.5 & 2.2 & 5.7 & 10.8 & 12.8 & 16.9 & 7.5 \\
\hline & 0.05 & 1.8 & 3.3 & 5.8 & 9.9 & 14.1 & 19.5 & 8.1 \\
\hline & 0.5 & 1.9 & 2.8 & 5.5 & 12.1 & 14.1 & 19.8 & 8.4 \\
\hline & 5 & 1.7 & 3.1 & 6.4 & 11.1 & 13.8 & 18.9 & 8.3 \\
\hline \multirow{4}{*}{$\begin{array}{c}\text { Ore } \\
\text { B }\end{array}$} & 0.0 & 1.4 & 2.8 & 5.1 & 9.4 & 8.3 & 13.7 & 5.7 \\
\hline & 0.05 & 1.4 & 2.5 & 4.6 & 9.1 & 8.9 & 12.7 & 5.5 \\
\hline & 0.5 & 1.2 & 3.6 & 6.2 & 10.1 & 9.3 & 16.3 & 6.5 \\
\hline & 5 & 2.3 & 3.5 & 6.5 & 9.9 & 9.5 & 16.1 & 6.8 \\
\hline \multirow{4}{*}{$\begin{array}{c}\text { Ore } \\
\mathrm{C}\end{array}$} & 0.0 & 3.5 & 4.2 & 3.3 & 2.8 & 2.6 & 5.2 & 3.9 \\
\hline & 0.05 & 2.2 & 3.9 & 6.1 & 13.8 & 15.4 & 18.4 & 10.0 \\
\hline & 0.5 & 1.8 & 3.1 & 5.2 & 13.7 & 16.1 & 20.9 & 10.3 \\
\hline & 5 & 1.7 & 3.6 & 5.7 & 13.8 & 16.3 & 21.8 & 10.7 \\
\hline \multirow{4}{*}{$\begin{array}{c}\text { Ore } \\
\text { D }\end{array}$} & 0.0 & 1.4 & 2.3 & 4.3 & 5.3 & 12.1 & 11.7 & 6.4 \\
\hline & 0.05 & 2.0 & 3.0 & 4.6 & 10.9 & 13.3 & 17.6 & 9.0 \\
\hline & 0.5 & 1.5 & 2.8 & 4.6 & 11.6 & 13.1 & 17.6 & 8.9 \\
\hline & 5 & 2.1 & 2.8 & 4.7 & 11.3 & 13.8 & 17.8 & 9.1 \\
\hline \multirow{4}{*}{$\begin{array}{c}\text { Ore } \\
\mathrm{E}\end{array}$} & 0.0 & 2.1 & 1.9 & 3.2 & 5.4 & 4.2 & 3.2 & 3.1 \\
\hline & 0.05 & 1.1 & 1.5 & 3.5 & 5.2 & 6.5 & 17.0 & 6.4 \\
\hline & 0.5 & 1.2 & 1.9 & 2.4 & 5.5 & 7.6 & 16.7 & 6.3 \\
\hline & 5 & 1.7 & 1.8 & 3.4 & 6.1 & 7.5 & 17.7 & 6.9 \\
\hline \multirow{4}{*}{$\begin{array}{c}\text { Ore } \\
F\end{array}$} & 0.0 & 0.0 & 0.0 & 0.0 & 0.6 & 1.8 & 0.8 & 0.4 \\
\hline & 0.05 & 0.0 & 0.1 & 0.3 & 1.3 & 1.6 & 1.4 & 0.9 \\
\hline & 0.5 & 0.6 & 0.9 & 1.0 & 1.6 & 2.3 & 2.7 & 1.8 \\
\hline & 5 & 0.8 & 1.1 & 0.9 & 1.7 & 2.5 & 2.9 & 1.9 \\
\hline \multirow{4}{*}{$\begin{array}{c}\text { Ore } \\
\mathrm{G}\end{array}$} & 0.0 & 2.0 & 2.2 & 4.3 & 7.9 & 7.2 & 6.4 & 5.6 \\
\hline & 0.05 & 1.1 & 2.1 & 3.8 & 8.0 & 7.1 & 7.5 & 5.8 \\
\hline & 0.5 & 1.4 & 2.4 & 4.5 & 8.7 & 7.5 & 8.1 & 6.4 \\
\hline & 5 & 0.6 & 1.9 & 4.9 & 8.9 & 8.2 & 8.5 & 6.7 \\
\hline
\end{tabular}

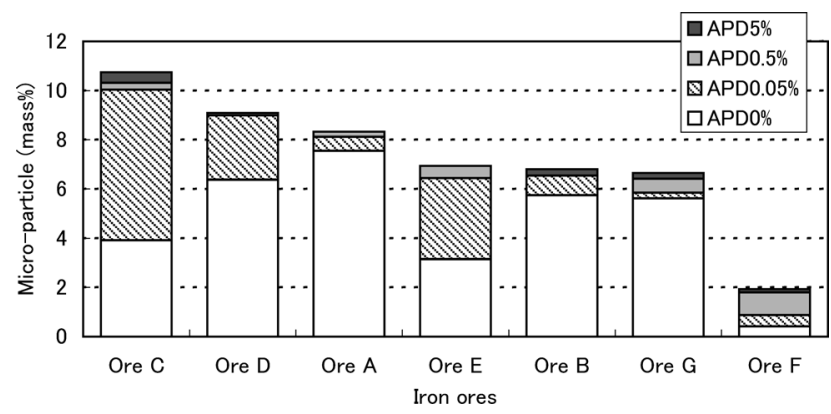

Fig. 2. Amount of iron ore micro-particle measured by Andreasen pipette method.

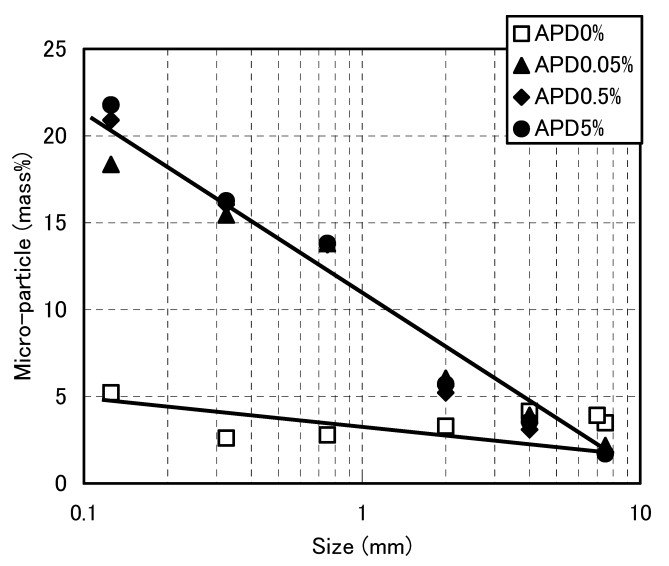

Fig. 3. Content of micro-particle in each split size for Ore C.

that the micro-particle dispersion effect of APD is not in direct proportion to the APD addition and that the effect is already saturated when APD is 0.05 mass $\%$.

Figure 3 shows the relationship between ore particle size and micro-particle for Ore $\mathrm{C}$ which contained the largest 


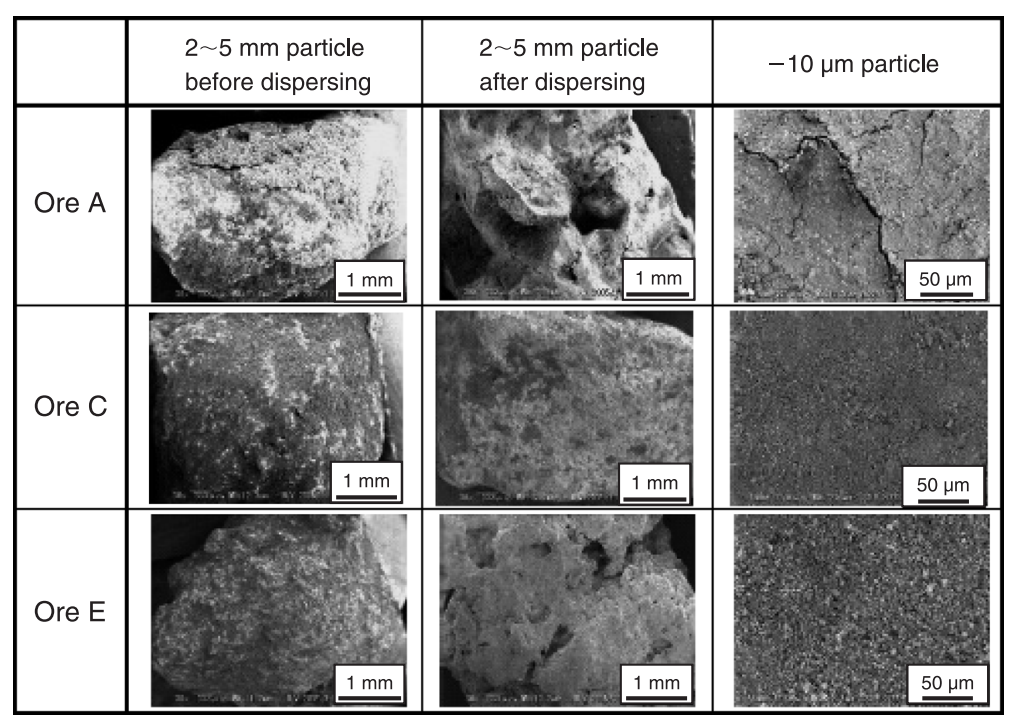

Fig. 4. Surfaces of scanning micro-scope image of iron ores and micro-particles as received and after water washing.

amount of micro-particles. When APD was not added, micro-particles were about 2 to 5 mass $\%$ over the entire ore size range. When APD was added, there was a tendency that the micro-particles increased with the decrease in ore particle size. This suggests that many of the micro-particles were present at the surface of the iron ore.

\subsection{Shape of Iron Ore Surface and Micro-particles}

Concerning Ores A, C and E, the shapes of iron ore surfaces before and after ultrasonic agitation and micro-particles were observed with SEM. The observation results are shown in Fig. 4. Ores $A$ and $E$ revealed a porous surface with cavities about 0.2 to $1 \mathrm{~mm}$ in size in the iron ore surface after liberation of micro-particles. Ore $\mathrm{C}$ had a dense surface, showing no cavities. Therefore, it is considered that micro-particles in Ores A and E were dispersed mostly from the cavities, whereas the micro-particles in Ore $\mathrm{C}$ were dispersed from the entire surface of the iron ore.

As for the shape of micro-particles, the compact of micro-particles in Ore A showed many cracks, whereas the compacts of Ores $\mathrm{C}$ and $\mathrm{E}$ showed no cracks. The microparticles of Ore $\mathrm{C}$ were mainly of submicron size, whereas those of Ore E were mainly about $10 \mu \mathrm{m}$ in size. It is considered that the main constituent of micro-particles is goethite for Ore A, clay for Ore C, and hematite for Ore E. These differences in physical properties of iron ores are considered to make the difference in micro-particle dispersion.

\subsection{Influence of Moisture and APD on Granulation}

The granulation test results are shown in Table 4. In the table, the hyphens indicate that the rolling was impossible because the moisture of the sample was so high that much of the sample stuck to the interior of the drum mixer. As a representative example, the relationship between granule moisture and particle size distribution in wet state for Ore $\mathrm{A}$ is shown in Fig. 5. Concerning $2 \mathrm{~mm}$ or less particle, there was a tendency that the proportion of those particles decreased in the high moisture region. A similar change in size distribution in wet state was observed with all the iron ores.
There was the specific moisture value at which the $0.25 \mathrm{~mm}$ or less particle in wet state was zero by extrapolation as shown in Fig. 6. The moisture was defined as the saturated moisture $\left(w_{\mathrm{s}}\right)$. The saturated moisture can be considered as one of the optimum moistures in the granulation. The saturated moisture for each iron ores is shown in Table 5. It was found that when APD was not added, the saturated moistures widely were 9.1 mass $\%$ for Ore C (Maramamba ore) to $5.6 \mathrm{mass} \%$ for Ore $\mathrm{F}$ (hematite ore). It was confirmed that as shown in Fig. 6, the saturated moisture showed a tendency to decrease when APD was added. There was a tendency that the APD causes the saturated moisture to decrease by 0.6 to 1.9 mass $\%$. Okada et al. ${ }^{15)}$ pointed out that APD liberates moisture in the micro-particle aggregate, which accelerates granulation. It may be said that the results of the present test represent much quantitatively the acceleration mechanism of granulation by APD.

\subsection{Influence of Moisture and APD on Degradation of Granules in Dry State}

As an example of the relationship between granulation moisture and degradation in dry state, the relationship between granulation moisture and proportion of $0.25 \mathrm{~mm}$ or less particle in dry state for Ore $\mathrm{C}$ is shown in Fig. 7. APD significantly decreased the proportion of $0.25 \mathrm{~mm}$ or less particle in dry state, suggesting that the degradation after drying could be substantially restrained.

The proportion of $0.25 \mathrm{~mm}$ or less particle in dry state became a minimum when the moisture was 7.5 mass $\%$. It is considered that the moisture at which the proportion becomes a minimum is also one of the optimum moisture in the granulation. Therefore, the moisture that minimizes the proportion of $0.25 \mathrm{~mm}$ or less particle in dry state was defined as minimum degradation moisture $\left(w_{\mathrm{d}}\right)$. The minimum degradation moistures for each iron ores are shown in Table 5. Despite under many different conditions, the minimum degradation moisture was smaller than the saturated moisture. This indicates that the optimum granulation moisture in wet state does not always coincide with the optimum moisture in dry state. The implication of this fact is that even when iron ore is granulated using the optimum 
Table 4. Wet and dry size distributions of granules and degradation after drying after granulation.

$(\operatorname{mass} \%)$

\begin{tabular}{|c|c|c|c|c|c|c|c|c|c|c|c|c|c|c|c|c|}
\hline & \multicolumn{8}{|c|}{ APD0\% } & \multicolumn{8}{|c|}{ APD0.5\% } \\
\hline & \multirow{3}{*}{ Moisture } & \multicolumn{6}{|c|}{ Wet } & \multirow{3}{*}{\begin{tabular}{|r||} 
Dry \\
-0.25 \\
$\mathrm{~mm}$
\end{tabular}} & \multirow{3}{*}{ Moisture } & \multicolumn{6}{|c|}{ Wet } & \multirow{3}{*}{$\begin{array}{r}\text { Dry } \\
0.25 \\
\mathrm{~mm}\end{array}$} \\
\hline & & $+5 \mathrm{~mm}$ & $2 \sim$ & $1 \sim$ & $0.5 \sim$ & $0.25 \sim$ & -0.25 & & & & $2 \sim$ & $1 \sim$ & $0.5 \sim$ & $0.25 \sim$ & -0.25 & \\
\hline & & & $5 \mathrm{~mm}$ & $2 \mathrm{~mm}$ & $1 \mathrm{~mm}$ & $0.5 \mathrm{~mm}$ & $\mathrm{~mm} \sim$ & & & & $5 \mathrm{~mm}$ & $2 \mathrm{~mm}$ & $1 \mathrm{~mm}$ & $0.5 \mathrm{~mm}$ & $\mathrm{~mm}$ & \\
\hline & 6.2 & 17.2 & 28.5 & 17.8 & 12.7 & 10.3 & 13.6 & 17.5 & 6.4 & 19.9 & 22.4 & 23.2 & 16.3 & 11.7 & 6.5 & 10.1 \\
\hline \multirow{5}{*}{ A } & 7.2 & 18.6 & 31.2 & 17.7 & 12.9 & 10.5 & 9.1 & 15.3 & 7.3 & 21.4 & 26.7 & 22.9 & 20.3 & 7.8 & 1.0 & 2.7 \\
\hline & 7.9 & 20.9 & 33.4 & 17.7 & 14.3 & 10.2 & 3.5 & 7.6 & 8.1 & 22.5 & 26.3 & 29.7 & 18.2 & 2.7 & 0.5 & 2.6 \\
\hline & 8.5 & 21.6 & 34.2 & 20.0 & 16.8 & 5.5 & 1.8 & 5.8 & 9.0 & 22.6 & 41.1 & 29.0 & 5.9 & 1.3 & 0.2 & 3.0 \\
\hline & 9.2 & 27.2 & 37.8 & 21.7 & 9.3 & 3.1 & 0.8 & 6.3 & 9.8 & 31.2 & 49.7 & 14.2 & 4.2 & 0.6 & 0.1 & 3.6 \\
\hline & 10.1 & 32.5 & 42.5 & 15.9 & 6.9 & 2.0 & 0.3 & 7.5 & $\frac{0.5}{10.3}$ & \begin{tabular}{|l|l}
48.6 \\
\end{tabular} & \begin{tabular}{|l|l|}
39.1 \\
\end{tabular} & 9.9 & 2.1 & 0.2 & 0.1 & 4.3 \\
\hline \multirow{6}{*}{$\begin{array}{l}\text { Dre } \\
\text { B }\end{array}$} & 5.9 & 19.0 & 28.3 & 14.0 & $\overline{11.9}$ & 10.1 & $\overline{16.8}$ & $\overline{22.6}$ & 6.1 & 21.5 & 27.5 & 18.4 & $\overline{16.1}$ & $\overline{12.6}$ & 3.9 & 7.6 \\
\hline & 6.6 & 21.9 & 27.8 & 17.3 & 13.5 & 10.6 & 8.9 & 15.4 & 6.9 & 23.5 & 35.1 & 24.5 & 12.0 & 3.9 & 1.0 & 6.6 \\
\hline & 7.4 & 23.3 & 31.5 & 19.0 & 13.2 & 7.8 & 5.2 & 15.1 & 7.8 & 35.1 & 37.6 & 17.6 & 7.8 & 1.5 & 0.4 & 7.0 \\
\hline & 8.2 & 25.4 & 39.8 & 15.9 & 10.8 & 6.0 & 2.1 & 17.6 & 8.6 & 50.9 & 31.8 & 13.6 & 3.1 & 0.4 & 0.2 & 7.4 \\
\hline & 8.9 & 35.9 & 39.3 & 13.1 & 8.6 & 2.7 & 0.5 & 20.0 & 9.0 & 64.0 & 29.9 & 5.1 & 0.8 & 0.1 & 0.0 & 8.2 \\
\hline & 9.6 & 43.6 & 36.5 & 14.7 & 4.4 & 0.6 & 0.1 & 20.5 & & & & & & & & \\
\hline \multirow{6}{*}{$\begin{array}{c}\text { Ore } \\
\text { C }\end{array}$} & 5.3 & 18.6 & 24.1 & 14.7 & 11.1 & 10.1 & 21.3 & 29.1 & 5.3 & 9.2 & 24.5 & 15.0 & 13.5 & 12.7 & 15.1 & 19.1 \\
\hline & 6.0 & 20.8 & 27.1 & 14.7 & 10.4 & 9.0 & 17.9 & 25.7 & 6.2 & 19.5 & 26.3 & 16.1 & 15.4 & 16.8 & 5.9 & 10.6 \\
\hline & 6.5 & 24.2 & 28.0 & 14.4 & 11.4 & 9.7 & 12.4 & 21.9 & 7.0 & 22.4 & 31. & 18.7 & 17.7 & 7.8 & & 6.6 \\
\hline & 7.5 & 25.0 & 29.6 & 17.3 & 12.2 & 8.7 & 7.2 & 18.9 & 7.9 & 25.3 & 39.3 & 19.5 & 12.2 & 3.1 & 0.6 & 7.4 \\
\hline & 8.3 & 28.1 & 32.8 & 18.2 & 10.9 & 6.2 & 3.8 & 21.1 & 8.6 & 43.8 & 34.4 & $\frac{1.0}{15.8}$ & 4.9 & 0.9 & 0.2 & $\frac{1.7}{73}$ \\
\hline & 9.1 & 28.1 & 40.3 & 15.4 & 9.9 & 4.7 & 1.5 & 23.5 & 9.3 & 51.9 & 36.6 & 9.3 & 1.9 & 0.2 & 0.1 & 8.2 \\
\hline \multirow{6}{*}{$\begin{array}{c}\text { Ore } \\
\text { D }\end{array}$} & 5.2 & 25.3 & 31.1 & 16.4 & 11.8 & 8.2 & 7.2 & 18.1 & 5.1 & 22.5 & 35.6 & 22.7 & 16.7 & 2.1 & $\overline{0.4}$ & 2.8 \\
\hline & 5.7 & 29.8 & 35.7 & 17.3 & 9.6 & 4.7 & 2.9 & 17. & 5.9 & 33. & 47.5 & 12.9 & 5.0 & 0.9 & 0.2 & 4.1 \\
\hline & 6.5 & 30.1 & 40.4 & 17.1 & 7.3 & 3.8 & 1.4 & 21.4 & 6.7 & 56.7 & 34.3 & 7.1 & 1.4 & 0.3 & 0.2 & 5.1 \\
\hline & 7.3 & 33.4 & 43.5 & 13.4 & 6.8 & 2.3 & 0.6 & 23.3 & 0.1 & & & & - & & & \\
\hline & 8.2 & 46.3 & 37.9 & 10.5 & 4.1 & 1.0 & 0.3 & 24.2 & - & & & & - & & & \\
\hline & & & & & & & & & & & & & & & & \\
\hline \multirow{4}{*}{$\begin{array}{c}\text { Ore } \\
\mathrm{E}\end{array}$} & 4.7 & & 30.6 & 18.3 & 12.1 & 8.9 & 6.8 & 22.2 & 5.0 & 26.3 & 40.7 & 18.8 & 10.5 & 3.0 & 0.7 & 5.9 \\
\hline & 5.4 & 28.6 & 33.4 & 16.9 & 11.3 & 6.9 & 2.9 & 22.1 & 5.6 & 43.7 & 39.2 & 12.0 & 3.7 & 1.0 & 0.3 & 5.8 \\
\hline & 6.0 & 35.9 & 33.2 & 17.3 & 8.8 & 3.2 & 1.7 & 20.2 & & & & & & & & \\
\hline & & & & & & & & & & & & & & & & \\
\hline \multirow{3}{*}{$\begin{array}{c}\text { Ore } \\
\text { F }\end{array}$} & 4.1 & 19.2 & 30.3 & 15.3 & 15.3 & 8.1 & 11.8 & 26.8 & 4.7 & 23.6 & 34.4 & 18.3 & 15.1 & 6.8 & 1.9 & 12.3 \\
\hline & 5.5 & $\begin{array}{l}19.8 \\
\end{array}$ & 32.9 & 26.7 & 15.1 & 4.3 & 1.3 & 26.9 & 5.6 & 24.9 & \begin{tabular}{|l|}
37.2 \\
\end{tabular} & 20.4 & 14.5 & 2.6 & 0.4 & 12.9 \\
\hline & & & & & & & & & & & & & & & & \\
\hline \multirow{6}{*}{$\begin{array}{c}\text { Ore } \\
G\end{array}$} & 5.0 & & 2.5 & 16.2 & 11.7 & 9.9 & 21.0 & 28.1 & 5.1 & 17.0 & 26.9 & 14.6 & 13.6 & 12.2 & 15.7 & 21.1 \\
\hline & 6.0 & 18.4 & 25.2 & 16.5 & 12.6 & 10.2 & 17.1 & 27.0 & 5.9 & 17.4 & 29.6 & 15.6 & 13.8 & 13.4 & 10.2 & 16.9 \\
\hline & 6.7 & 21.7 & 25.6 & 18.0 & 11.9 & 10.0 & 12.7 & 25.5 & 6.8 & 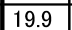 & 31. & 14.8 & 15.0 & 12.6 & 5.8 & 13.3 \\
\hline & 7.4 & 21.5 & 27.7 & 19.5 & 12.5 & 10.7 & 8.1 & 25.9 & 7.8 & 21.8 & 34.6 & 16.4 & 17.1 & 7.7 & 2.4 & 13.4 \\
\hline & 83 & 221 & 289 & 213 & 148 & 86 & 44 & 259 & 86 & 252 & 357 & 176 & 161 & 46 & 08 & 134 \\
\hline & 9.1 & 22.0 & 36.1 & 21.8 & \begin{tabular}{|l|l}
14.6 \\
\end{tabular} & 4.2 & $\begin{array}{l}.7 \\
1.3\end{array}$ & 26.9 & 9.3 & \begin{tabular}{|l|l}
28.7 \\
\end{tabular} & \begin{tabular}{|l|l}
42.2 \\
\end{tabular} & 20.7 & 7.8 & 0.5 & 0.1 & 16.2 \\
\hline
\end{tabular}

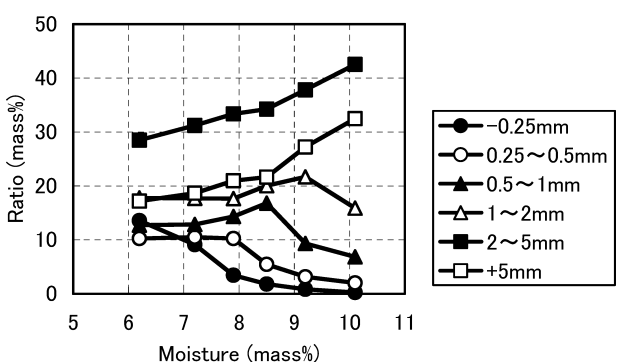

Fig. 5. Relation between size distribution of Ore A after granulation and moisture.

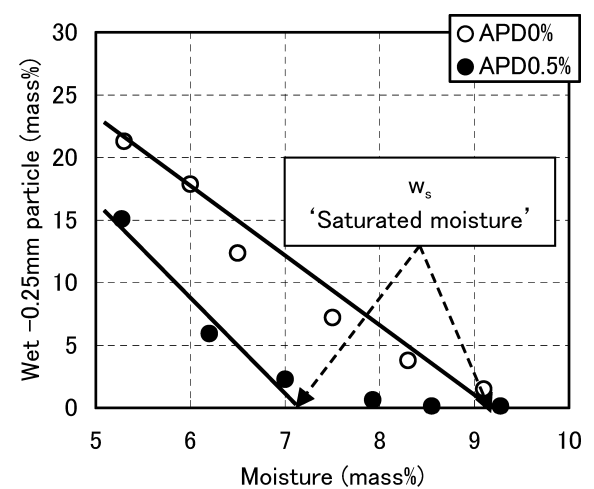

Fig. 6. Relation between wet $-0.25 \mathrm{~mm}$ particle and moisture with or without APD.
Table 5. Saturated moisture $\left(w_{\mathrm{s}}\right)$ and minimum degradation moisture $\left(w_{\mathrm{d}}\right)$ for each ore with or without APD.

\begin{tabular}{|c|c|c|c|c|}
\hline \multirow{2}{*}{} & \multicolumn{2}{|c}{ APD0\% } & \multicolumn{2}{c|}{ APD0.5\% } \\
\cline { 2 - 5 } & $\mathrm{w}_{\mathrm{s}}$ & $\mathrm{w}_{\mathrm{d}}$ & $\mathrm{w}_{\mathrm{s}}$ & $\mathrm{w}_{\mathrm{d}}$ \\
\hline Ore A & 8.7 & 8.5 & 7.5 & 8.1 \\
\hline Ore B & 8.3 & 7.4 & 7.1 & 6.9 \\
\hline Ore C & 9.1 & 7.3 & 7.2 & 7.0 \\
\hline Ore D & 6.2 & 5.7 & 5.0 & 5.1 \\
\hline Ore E & 6.0 & 6.0 & 5.0 & 5.6 \\
\hline Ore F & 5.6 & 4.1 & 5.0 & 4.7 \\
\hline Ore G & 9.2 & 6.7 & 8.1 & 6.8 \\
\hline
\end{tabular}

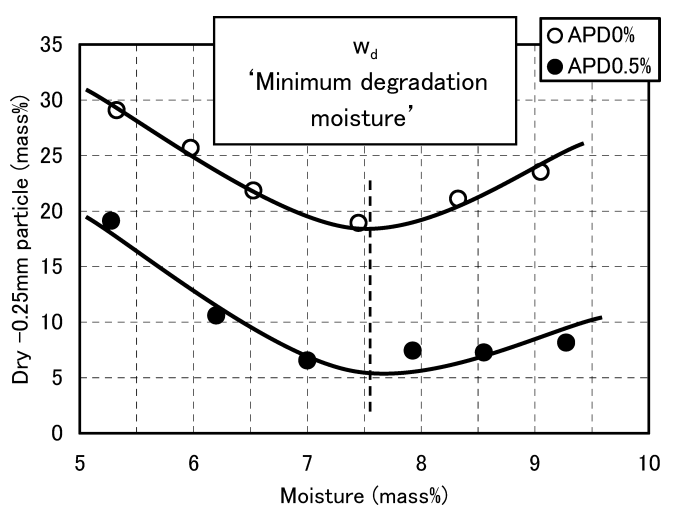

Fig. 7. Relation between dry $-0.25 \mathrm{~mm}$ particle and moisture with or without APD. 


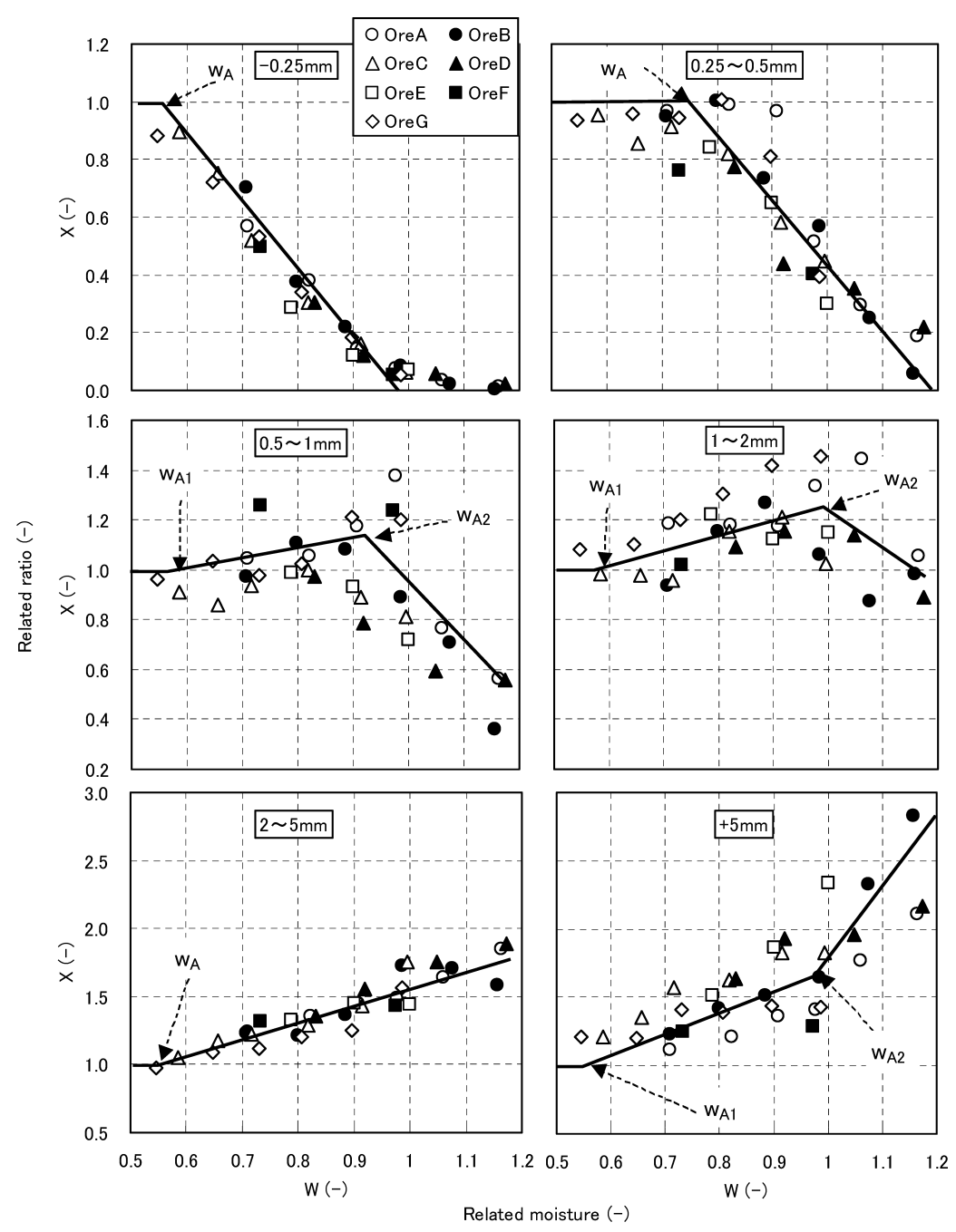

Fig. 8. Relation between wet size distribution after granulation and relative moisture $(W)$.

moisture in wet state, it is intrinsically unavoidable to exceed the optimum moisture at which the degradation in dry state is minimized. The minimum degradation moisture did not change significantly with APD. Thus, when APD is added, the saturated moisture decreases, while the minimum degradation moisture remains almost the same. It is considered that APD also has the effect to reduce the difference between the optimum granulation moisture in wet state and in dry state.

\section{Discussion}

\subsection{Granulation Phenomenon in Wet State}

In order to interpret the iron ore granulation in a unified formula, we summarized the test results shown in Table 4 by making them dimensionless. With the saturated moisture $\left(w_{\mathrm{s}}\right)$ for each iron ore used as the base, the granulation moisture $(w)$ was made dimensionless and defined as the relative moisture $(W)$. In addition, the proportion of wet particles in size class i was made dimensionless by the initial proportion of particle size and defined as the relative proportion $\left(X^{i}\right)$. The results shown in Table 4 that are re-expressed using $W$ and $X$ are shown in Fig. 8. By using the concept of relative moisture, granulation behavior in wet state could be expressed in an almost unified formula for all ores. In addition, by using the moisture at the point of in-
Table 6. Parameters and application range of Eq. (5).

\begin{tabular}{|c|c|c|c|c|}
\hline $\mathrm{i}$ & $\mathrm{X}^{0}$ & $\alpha$ & $\mathrm{w}_{\mathrm{A}}$ & Application \\
\hline-0.25 & 1.00 & -2.20 & 0.55 & $0.55 \leqq \mathrm{Z} \leqq 1.0$ \\
\hline $0.25 \sim 0.5$ & 1.00 & -2.20 & 0.75 & $0.75 \leqq \mathrm{Z} \leqq 1.2$ \\
\hline \multirow{2}{*}{$0.5 \sim 1.0$} & 1.00 & 0.50 & 0.55 & $0.55 \leqq \mathrm{Z} \leqq 0.92$ \\
\cline { 2 - 5 } & 1.20 & -2.20 & 0.92 & $0.92 \leqq \mathrm{Z} \leqq 1.2$ \\
\hline \multirow{2}{*}{$1.0 \sim 2.0$} & 1.00 & 0.50 & 0.55 & $0.55 \leqq \mathrm{Z} \leqq 1.0$ \\
\cline { 2 - 5 } & 1.23 & -2.20 & 1.00 & $1.0 \leqq \mathrm{Z} \leqq 1.2$ \\
\hline \multirow{2}{*}{$2.0 \sim 5.0$} & 1.00 & 1.43 & 0.55 & $0.55 \leqq \mathrm{Z} \leqq 1.2$ \\
\hline \multirow{2}{*}{+5} & 1.00 & 1.43 & 0.55 & $0.55 \leqq \mathrm{Z} \leqq 0.92$ \\
\cline { 2 - 5 } & 1.53 & 4.23 & 0.92 & $0.92 \leqq \mathrm{Z} \leqq 1.2$ \\
\hline
\end{tabular}

flection, which is defined as the adhere starting moisture $\left(w_{A}^{i}\right)$, it is possible to express the test results for all ores by the relationship shown in Eq. (5). The scope of application of Eq. (5) is shown in Table 6, and the calculation results are shown by the straight lines in Fig. 8. Thus, by previously obtaining the value of $w_{\mathrm{s}}$, it is possible to predict the particle size distribution at any moisture.

$$
X^{i}=X^{0}+\alpha\left(W-w_{\mathrm{A}}^{i} / w_{\mathrm{s}}\right)
$$

$W=w / w_{\mathrm{s}}: \quad$ Relative moisture $(-)$

$w$ : Granulation moisture (mass $\%$ )

$i$ : $\quad$ Particle size class (mm)

$\alpha$ : Constant of proportion (-) 
$W_{\mathrm{A}}^{i}$ : Flexion moisture (mass $\%$ )

$X_{0}$ : Flexion particle ratio $(-)$

\subsection{Evaluation of Saturation Degree on Granulation}

In the field of powder technology, saturation degree is often used as an index for evaluation of a granule structure in wet state. ${ }^{17,18)}$ Saturation degree refers to the volume ratio of moisture to the volume of space among particles in a granule. When moisture fills up the entire volume of space, saturation degree is 1.0. Sekiguchi et al. ${ }^{17)}$ have reported that in order for granules to become sticky, it is necessary that the moisture should be higher than a threshold value, and that the fine particles become pasty when saturation degree exceeds 1.0. Since saturation degree is difficult to measure, it has seldom been used in an analysis of iron ore granules.

Assuming that saturated moisture shown in Table 5 represents the condition under which saturation degree is virtually 1.0 , the change in particle size distribution due to an increase in moisture can be interpreted as follows. In the region in which $W$ is 0.55 or more, the proportion of $0.25 \mathrm{~mm}$ or less particles begins to decrease and the proportion of $0.5 \mathrm{~mm}$ or more begins to increase. This region is considered as one in which $0.25 \mathrm{~mm}$ or less particles stick to larger particles to form a granule. Since saturation degree at this point is less than 1.0, the sticking between particles is considered due to a water bridge. As the moisture is raised, the amount of water bridge increases. When $W$ is increased near $0.75,0.25$ to $0.5 \mathrm{~mm}$ particles begin to stick together. When $W$ is further increased to 0.9 to 1.0 , even 0.5 to $2 \mathrm{~mm}$ particles that have been increasing in proportion begin to decrease in proportion. As a result, it is considered that these intermediate-sized particles begin to be taken in larger particles. When $W$ is around 1.0, the sticking of all $0.25 \mathrm{~mm}$ or less particles to larger particles is completed. When $W$ exceeds 1.0 , the proportion of $5.0 \mathrm{~mm}$ or more particles increases sharply. According to Sekiguchi et al., when saturation degree exceeds 1.0 , it is considered that the iron ore have the liquefaction, in which the iron ores become pasty and the rolling becomes impossible. Micrographs of adhered layers of Ore $\mathrm{B}+5 \mathrm{~mm}$ granules are shown in Fig. 9. With the increase in granulation moisture, even coarse particles have been taken in larger particles. When $W=1.16$, not only $0.25 \mathrm{~mm}$ or less particles but also particles 0.25 to $0.5 \mathrm{~mm}$ in size have stuck to the nuclear particle. This result is considered to validate the conception mentioned above.

Therefore, the conception based on saturated moisture should be able to be used as a basic theory for explaining more systematically the iron ore granulation phenomenon that has so far been analyzed by using mainly granulation indexes such as particle size and degradation data.

\subsection{Interpretation of Granulation Phenomenon Tak- ing Micro-particle Behavior into Consideration}

The relationship between the increase of micro-particles and the decrease in saturated moisture with APD is shown in Fig. 10. The micro-particle volume was calculated on the assumption that true density of the micro-particles was $4000 \mathrm{~kg} / \mathrm{m}^{3}$. From Fig. 10, it was found that large increase of micro-particles resulted in large decrease in saturated

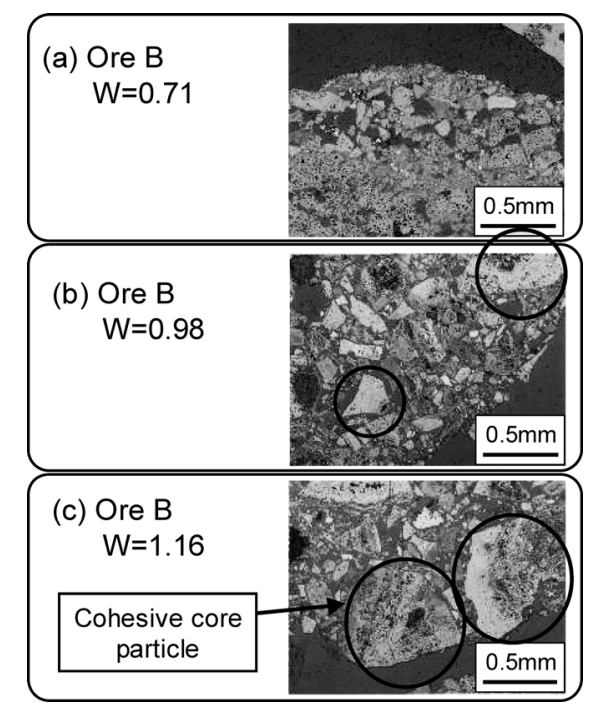

Fig. 9. Observation of cross-section of granules with change of relative water.

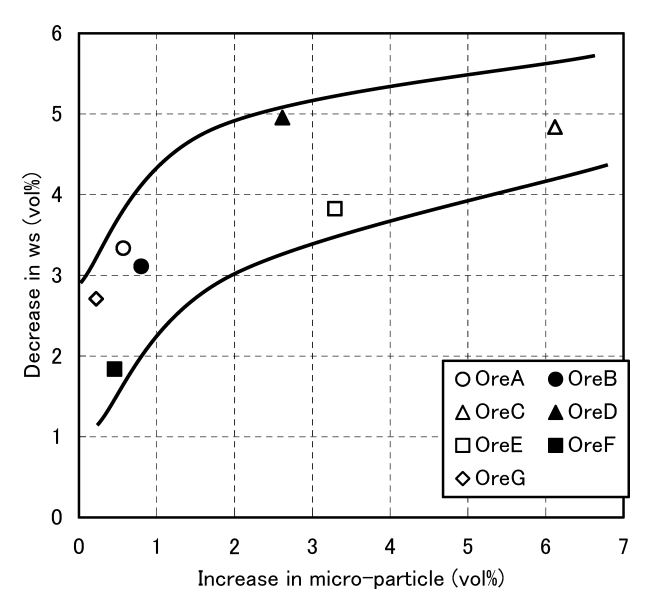

Fig. 10. Relation between the decrease in $w_{\mathrm{s}}$ and the calculated volumes of micro-particle dispersed with APD.

moisture. The reason for this is considered that as the micro-particles in ore are dispersed in water, the effective amount of iron ore particles decreases, whereas the volume of the liquid phase increases. In this case, even when the amount of increase of micro-particles was 1 vol\% or less, the decrease in $w_{\mathrm{s}}$ was relatively large. The reason for this is unclear, but it is conceivable that APD might have caused the arrangements of nuclear particles and fine particles to become dense, thereby causing the volume of space within the granules to decrease. The causes of these phenomena have to be clarified in further study.

The relationship between the minimum value of $0.25 \mathrm{~mm}$ or less particle degradation in dry state and the amount of micro-particles is shown in Fig. 11. The large amount of micro-particles is the small minimum value of degradation in dry state. Therefore, it is considered that the force required to keep the fine particles stuck to the nuclear particles in dry state is arisen from micro-particles. Namely, it is considered that in the process of the change from the wet state to the dry state, micro-particles concentrate at the water bridge and ultimately form a solid bridge, thereby producing the force for keeping the fine particles stuck to the nuclear particles.

The image of the granulation phenomenon prepared from 
the above results is shown in Fig. 12. When APD is added, micro-particles in the iron ore are dispersed into water, causing the effective amount of the liquid phase to increase. As a result, saturation degree increases, allowing for ore granulation with a lesser amount of water. With the movement of water in the drying process, the dispersed microparticles concentrate in the bridge between particles and form a solid bridge at the end of the drying process. The bond strength increased by the solid bridge is considered to restrain the degradation in the dry state.

The above interpretation of the granulation phenomenon taking into consideration the saturation degree and the movement of micro-particles is consistent with the increase in strength of granules by the use of a binder (e.g., quicklime or bentonite) and the improvement in granulation ability by the application of strong mixing using a high-speed agitating mixer, etc. The addition of a binder, such as quicklime or bentonite, can be regarded as a means of adding micro-particles from the outside. With respect to strong mixing for improving the granulation, it can be interpreted as a technique for mechanically dispersing microparticles in iron ore effectively. In further study, it should be required to establish a more comprehensive theory on the granulation by focusing on the behavior of micro-particles.

\section{Conclusions}

The following findings were obtained by quantification of micro-particles in iron ores and granulation tests.

(1) Micro-particles $10 \mu \mathrm{m}$ or less in size existed in any particle of any iron ore. The amount of those micro-particles and the effect of a dispersant widely differed from ore type. This is considered due to the differences in physical properties of micro-particles and in characteristics of ores

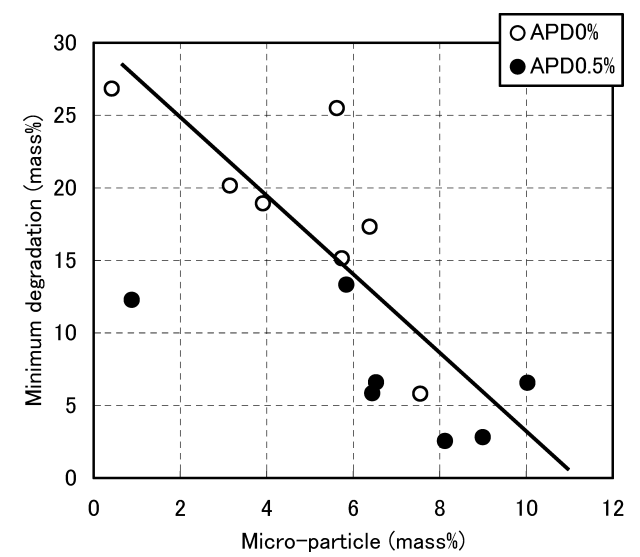

Fig. 11. Relation between content of micro-particle of iron ores and minimum degradation after drying. involving with the distribution state of micro-particles.

(2) By making the granulation moisture dimensionless through use of the moisture at which the degradation of $0.25 \mathrm{~mm}$ or less particles in wet state was zero (saturated moisture), it was possible to express the granulation behavior of any ores in a unified formula. It was possible to predict readily the particle size distribution at any moisture by using the saturated moisture previously measured.

(3) The optimum moisture for granulation in wet state is higher than that in dry state. The addition of a dispersant allowed granulation at a lesser moisture and permitted reducing the difference between the optimum moisture in wet and dry state. This was attributable to an increase in the effective amount of liquid phase when micro-particles in iron ore are dispersed into water.

(4) The micro-particles that have been dispersed into water form a solid bridge at the end of the drying process, and the solid bridge helps restrain the degradation of granules in dry state. It is considered that the development of such strength of granules is the fundamental contribution of a dispersant in improving the granulation of iron ore.

\section{REFERENCES}

1) K. Higuchi, T. Kawaguchi, M. Kobayashi, Y. Hosotani, K. Nakamura, K. Iwamoto and M. Fujimoto: ISIJ Int., 40 (2000), 1188.

2) H. Suzuki, H. Kurokawa, H. Yoshida, S. Kabuto and H. Iida: CAMPISIJ, 8 (1995), 905.

3) T. Inazumi, M. Fujimoto, S. Kasama and K. Sato: Tetsu-to-Hagané, 77 (1991), 63.

4) N. Ooyama, K. Igawa, K. Nushiro, M. Ida and N. Fujii: Tetsu-toHagané, 86 (2000), 309.

5) A. Morita, H. Toda and Y. Nosaka: Tetsu-to-Hagané, 55 (1969), S440.

6) Y. Ishikawa, K. Sugawara and Y. Umezu: Agglomeration 77, Proc. of the 2nd Int. Symp. on Agglomeration, (1977), 503.

7) T. C. Eisele and S. K. Kawatra: Miner. Process. Extract. Metall. Rev., 24 (2003), 1.

8) Y. Niwa, N. Sakamoto, O. Komatsu, H. Noda and A. Kumasaka: Tetsu-to-Hagané, 78 (1992), 1029.

9) T. Haga, A. Ohshio, K. Nakamura, T. Kozono and K. Uekawa: Tetsuto-Hagané, 83 (1997), 103.

10) T. Kawaguchi, K. Kuriyama and S. Sato: Tetsu-to-Hagané, 76 (1990), 1642.

11) T. Matsumura, K. Miyagawa and Y. Yamagata: Tetsu-to-Hagané, 92 (2006), 728.

12) S. Sato, M. Yoshinaga, M. Ichidate and T. Kawaguchi: Tetsu-toHagané, 68 (1982), 2174.

13) M. Matsumura and T. Kawaguchi: Tetsu-to-Hagané, 87 (2001), 290.

14) K. Sato: Fusen, 28 (1981), 99.

15) T. Okada, J. Okazaki, M. Nakano, K. Kawano and S. Miura: Tetsuto-Hagané, 92 (2006), 735.

16) Shoho Kagaku Kogaku, Izumi Shobo, Tokyo, (1969), 267.

17) I. Sekiguchi: Funtai Kogaku Kaishi, 26 (1989), 586.

18) S. Iveson, J. Lister, K. Hapgood and B. Ennis: Powder Technol., 117 (2001), 3 .

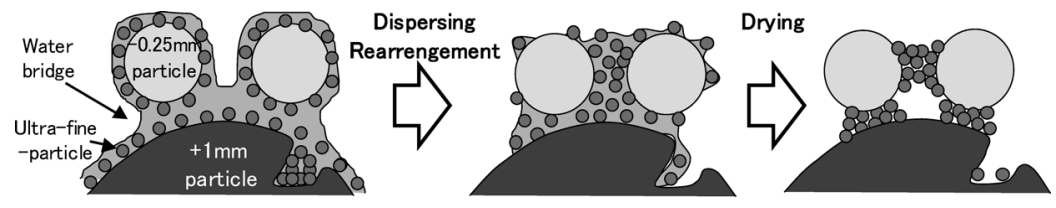

Fig. 12. The behavior of micro-particle on granulation. 